\title{
Speed and Memory: An Interview with Jane Miller
}

I first encountered Jane Miller through her 1993 book August Zero. With a vertiginous lyricism, at turns sacred and profane, intimate and cultural, she managed to render an apocalyptic vision without losing an essential tenderness. It was a model to me of the possibilities of lyric form, and specifically how I, also a western poet, might turn my gaze outward to the physical landscape while maintaining the imperatives of song. So too, her range-between love and devastation, gay and straight, postmodern and tradition-offered a way to write poetry that evoked the strange trespasses technology bears upon the self. I found her inspirational.

MC: Memory at These Speeds: New and Selected Poems opens, "From Brazil to Miami to a roadside motel to a super billboard/above Vegas's Stardust you are in vast spaces/at high speeds all watt and animation" ("Early American"). This sense of "vast spaces at high speeds" seems emblematic of much of your work in its obsession with real and imagined landscapes, travel, cinematic point of view, and the disjunction technology imposes on language and the individual. How has your work been a sustained effort at mapping this hyperreal contemporary landscape?

JM: We're still coming to terms with advances made in art nearly a century ago, developments such as stream-of-consciousness writing and other syntactical events, synchronicity, flashback, etc. As events have sped up, artists have looked for even more leverage in the language to halt the aggression. My map of the landscape is visual, and not just because I was a painter in my early twenties or because I've always loved to go to the movies. It's for the same reason most of us are visual-that's the sense that's been most bombarded. Look at my military term-it's been an "assault" - there's another fighting word; "advanced" society certainly is predatory. I've tried to slow the onslaught by reading the density of experience, magnifying it- "exploding the view" in map-maker's terms: but look, there's another troubling metaphor. 
MC: How has the physical landscape of the desert west-its vast spaces and limitless speeds-figured in that development?

JM: When I moved west, I felt my poems open to include more activity. Out west, everybody gets the physicists' "time is space." This might have led me to narrative poetry-time and place-but I became more interested in "time" and "space." In a poem, in lyric poetry especially, I love the stopped time/real life feeling. The open west provides some transcendental allure. But I don't feel like a regional writer because I don't understand the landscape enough to be able to foreground it.

David Hockney's paintings are a good example, and his influence, that of the Chinese scroll, is wonderful to examine; I came to admire art which flattens and, at the same time, is inclusive. All the while moving along in real time, his day-in-the life-of-Chinesemerchants scrolls along in red, delightfully adorned, but eventually, the scenes will "all add up," the whole greater than its parts.

MC: That suggests the landscape of your most recent volume of poetry, Wherever You Lay Your Head. The poems deal with the "nuclear imagination," both the origins and production of nuclear weapons, and the effect of their dissemination and acceptance ideologically. They're also about place-the western United States and Japan.

JM: My attraction to the Chinese scroll turned into a study of Japanese nineteenth-century artists, especially the master woodcut printmaker Ando Hiroshige. He presents scenes of pre-industrial Japanese life with honesty and tenderness. During his time, the Japanese middle and lower classes were beginning to explore life on the road, for business and pleasure. $\mathrm{He}$ is able to render the acute feelings of innkeepers, servants, cooks, travelers, prostitutes, and so on, with simple lines and elemental color. Although of another time and place (in many ways a golden era, despite the hardships), these prints encouraged me to write more directly. In studying Hiroshige's prints, I noticed how much he was willing to give up of himself in order to make contact with his audience. If he depicted rain darkening the sky, he would provide a glance-part sadness, part wonder-to complicate the frame, which enlarges our perception. When he did simplify a setting, literally moving mountains, it was to highlight the familiar for the viewer, who was 
all too aware of the surrounding terror. His altruistic imagination is at work. After studying nineteenth-century landscapes-pastoral Japan, frontier America-I had to face more recent US/Japanese history. The development of the bomb in laboratories in the American southwest, mid-twentieth-century, obviously has had dire physical and symbolic consequences.

MC: Actually and metaphorically, considering the bomb must have been perilous. How did you deal with the strain of working with such traumatic material? More largely, how does one write a political poetry in America?

JM: The more I studied, the more I didn't understand. I was overwhelmed, at various times, by grief, compassion, fear, and admiration. I never could quite drain myself out of the work. But I hope that the voice of the poet is not clever, not hysterical, not judgmental. I feel, at once, obliged to respond emotionally and obliged to let the trauma speak. It seems that the more I learned about the mass deaths caused by the bomb, the shorter the poems became, and the more particular the imagery. After reading books about the leveling of Nagasaki, all I could see in my head were two waitresses pedaling to a noodle shop downtown on their way to work of a morning, and the street stops, their lives stop, and the shop is a memory.

The challenge to confront politics in poetry is ample. I like to remember that the word is from the Greek: polis, of the people. So, political poetry is "only" about people. Ideological talk in poems is reckless. Speechmaking is a separate form altogether. But there have got to be ways to document life, in musical language, which reveal how power is exercised in society. Of course, one never knows how such a poem will turn out, what it will say, because music and reportage are blended in a subterranean place in a poet's psyche.

Adrienne Rich cleared up the matter for my generation of writers by reminding us that the personal is political. I suppose it comes down to finding the deepest place within oneself out of which to dredge the poem. The surface level of opinions about this or that won't work. Then there are masks through which the poet can speak. This is rhetorical poetry and it can work very well (think of Frank O'Hara). I'm more drawn to a mix of modes, but I think there is none better than the lyric for nearly everything. When Lorca goes over 
and over the hour at which his friend is killed, "at 5 o'clock in the afternoon," blaring it every other line in midst of a quasi-narrative ["Lament for Ignacio Sánchez Mejías"], the lyric bell becomes nightmarish, incantatory, hallucinatory. We "get" a subliminal message that is paradoxical and profound. I suppose political poetry has this quality of stepping outside of fear. If lyrical sound is compelling-for its music, its surprise, its mystery, its multiplicity-it can overcome the personality of the writer. It will have an impersonal voice of its own. It's funny, isn't it, that lyric poetry is so often associated with the self, the personal, but it is also powerfully universal.

MC: Speaking of multiplicity and a mixing of modes, you've just finished a memoir, Seven Mediterraneans. That's a new direction.

JM: I wanted to try a new form. After I wrote Wherever You Lay Your Head, and learned about the lives of the nineteenth- and twentieth-century Japanese, especially lives that had been devastated by the war, I stopped writing. The writing life seemed so privileged (although also necessary-I really believe in art as a force in the universe). I felt lucky to be alive, given the vast number of things that could go horribly wrong. I got drawn back into writing because-as with anything or anyone one loves-I couldn't stay away, and I guess writing became a part of my life again. I wrote quickly so I wouldn't be at a desk too many hours a day. Mostly I wrote Seven Mediterraneans the way poets write poems, in bursts. You can say this book is a memoir, but I wrote it as a long poem, as much for the music as for the meaning.

MC: The question of genre is really compelling in Seven Mediterraneans. It's travel literature, memoir, fiction, even, as you say, a long poem. How did the notion of genre affect the writing?

JM: The conceit developed slowly; I'd carried the title around for years. One day I'd written the title in a notebook, probably because I liked the rhyme, but I didn't know to what it referred-to seven people? places? feelings? It took a while to figure out that I didn't have to choose. I'd always wanted to write a paean to the region, a gesture of love and appreciation. These were my experiences: these were the artists and writers I studied, and I had a girlfriend whose 
father was a colonel in the Greek army. But after a love affair is over, the emotions the place calls up keep coming. Let me put it another way. Years later, on a visit to Greece with someone else, there was an old man who'd picked and cleaned pounds and pounds of oregano, and he was sitting with burlap sacks of the fragrant herb on a rock in front of-naturally! who could make this up?-Yannis Ritsos's old house in Monemvasia. We bought some, and couldn't believe our good fortune, and tried to pay "extra" (what amount could compensate him?), and he kissed us. This is all in two, three minutes, with the great sea behind the house, and the hills where he picked the herbs in front, and the three of us in an ancient transaction, money for goods. He was overworked and underpaid, we were visitors with good noses. This transaction is thick with politics, culture, personal history, geography, sensuality, food, wine, goats, tourism, poetry, mythology....

MC: Perhaps it's better to call it a meditation, a meditation on place, on the profound inscriptions place provides.

JM: I'm glad you see it as a meditation; my preoccupation here, the love story, happens in (is inspired by?) a real place, and the place dictates the style and tone. Recently, Anne Carson said in an interview-she was speaking about marriage - that the story as story needs to be about struggle and dissatisfaction and suffering because happiness doesn't have much to say for itself, sadly. Well, I wondered if I could write about heartbreak and loss and have them be overwhelmed by beauty, the beauty of place, so much that happiness would win out. Sure, I've read all about the death of love and romance. But remember, I'm trying to write over-the-top, roiling sentences so the impression might be one of joy in the face of loss, as if language itself could be an ameliorating force. Joy's still OK, isn't it? I asked myself whom I would have to be in order to love what happens in life, whatever happens, and where I might be and write from, and what kind of language it would take to represent that. Not that I feel Pollyannaish. Believe me, I hate murderers. I'm scared of war. I've struggled with my mother, etc. There are moments during which even a sunset hurts somebody. I know that struggle and suffering are serious business, tragic sometimes. Meditating on place helped broaden my views of those feelings. My effort went into renewing 
a contact with the spirit of a place, and my strategy was to think through my feelings. I hope "my" love life fades in the process, and that the metaphoric and actual place is inviting.

MC: What strikes me in all of your poems and essays about travel is their effort at recovery, an attempt to find meaningful rituals and symbols of connection - to lovers, community, the body, the environment, etc. The paradox of leaving to find home is always present.

JM: Voluntary exile is liberating. I can hear English better when I'm out of it. I can escape from what I think of as the "middle distance" view of things. I like the vantage point that is microscopic or macroscopic. It's true that I can get there in my normal life, whatever that means, but as the stranger, it is easier and faster.

I love being alone, and I think artists in general do, as long as it doesn't turn into loneliness. The way I deal with it is to try to stay connected to that which is deepest in all of us, far into the collective unconscious (Jung's way of putting it), at home amid the figures of language, especially the nouns, which come alive, to me, set to music. I like to think of them as figures, with bodies that make sounds, rough or slippery or piercing or comforting sounds. There's a reason why a word such as "stone" has such connotative value in our culture. That solid " $n$ " at the end, and the open "o," demonstrate visually how they are (the little archway of the "n," the open porthole of the "o," etc.). When language reveals its embodiment to me, I feel grounded. And that enables me to believe there is a world, and I have responsibilities. How beautiful the phrase of Delmore Schwartz: "In dreams begin responsibilities."

MC: I wonder if you might talk a bit about the line. Yours maintains a very slippery countermeasure, a verticality that resists the closure of the sentence while maintaining a kind of discursivity that is nonetheless highly musical. From what l've seen of your new book, A Palace of Pearls, the poems are closer to the sentence than ever, and yet they "run on," use no punctuation, insist on verticality.

JM: As close as we've come to prose, I think poets still need the confrontation with closure at every turn. "Here's death," the line says, 
here's your next negotiation, coming at you furiously. It ups the pressure. Simply living, getting closer to the literal end changes the line.

A Palace of Pearls attempts to wonder about the poet's responsibility in times of war. I tried, with a long line, to replicate the mind's, or the body's, response to overwhelming pressure-how the thinking keeps on coming, admitting everything, in both senses of that term. My long lines deal with the Judaic, Christian and Muslim triangulation, and I've literally tried to layer those worlds by associations and sounds. Then, too, this is probably my most personal book, in that although I was at home, one hot desert summer, the world very much invaded. That seemed most appropriate, given the world's emergency state now.

MC : I'd like to introduce the term "poetry of witness." Its current usage, as suggested by Carolyn Forché, applies more often than not to that species of political witness existent in war-torn countries. From Ahkmatova to Milosz, to name just two exemplary voices, the necessity to bear witness to human atrocity seems vital. Yet it's a complicated term. What does it mean to you, and what does an American poet bring to the act of witness?

JM: What we live and witness, as middle class Americans, is a step removed from the atrocities in Against Forgetting. It is the problem of viewing life from the "middle distance." Or is it? We wrestle with psychological and psychic demons, to be sure, and are accountable. This accountability to others and to ourselves places us in the same moral universe that poets of extremity inhabit. But there is no mistaking the difference, and it has partially paralyzed a generation of writers, who receded, in my opinion, into a comfortable narrative exegesis of psychological warfare, using word play, wit, self-consciousness, and experimentation with form (at content's expense). We all suffer this, to some degree. We have had great poetry recently in English, certainly, but those of us who have spent sheltered lives here look to poets who have experienced atrocity, and we revere them. How ironic: in a shadowy perversity, those poets who suffered are now intimidating us! The last thing they would want!

When you ask what an American poet can bring to the poetry of witness, the answer to simply document, with integrity, that which occurs, is suspect. We take witness to mean bystander, outsider, 
intruder, voyeur. We feel we might misrepresent. The options have been: to turn inward, recording the personal, which at least returns to others their privacy; to invent a world to witness, one somewhat recognizable, and so to investigate "reality" non-invasively; to record the world and openly reveal our shame at our limited experience; to address the atrocities we have not participated in, but heard about. All of these regard the poetry of witness as a social phenomenon. We shouldn't call a poem describing the light falling into a restaurant the poetry of witness, unless the restaurant were the site of some physical calamity (of course, some people have never been in a restaurant, so there's that layer to deal with). But lyric poetry-brief, crystalline bursts of emotion-has begun to give us back our intensity, our integrity. We no longer have to write haltingly, self-consciously. Lyric engagement, by necessity, speaks again-because it speaks from the soul-to ethical concerns. It's been said that women have ushered in this lyric renaissance. I don't know. Women certainly have had reasons to want to stop deifying, in general.

It's true that, in America, marginalized poets have done a good bit of witnessing about their situation. But there's no comparing a lack of health insurance because one is gay, say, to being put into a prison camp for being gay. I would say that an incantation is a beginning, a way American poetry is returning to reality, to truth. Language poetry, postmodernism, have taken us part way-that was their excitement. But the self-consciousness, the cleverness, has been debilitating. One breakthrough occurred in art because of the health crisis of AIDs. It gave permission: language may now again serve us very directly to express intimate human matters. The lyric is communal. It is a song beyond meaning. This non-narrative cry from the heart is vital. Any human emotion is worthy of language, and language which represents that which is good and decent in us - that is, love poetry-is of the essence.

MC : A related question, then. The rapid proliferation of creative writing programs in the past fifteen or so years has had a pernicious effect on the craft, or has it? As a professor at a major university, and as someone actively involved in the poetry business, what is your reaction to this commodification? How do you resist being a "university poet" producing other "university poets"? 
JM: I honestly don't get the disparaging of writing programs. Do people criticize as vociferously the conversation that went on in the bars Picasso and others hung out in, painters and sculptors arguing and drinking? What about in the salons of Paris, people eating dinner long into the night and arguing about art? These situations are privileged, to be sure, but art will be made regardless of circumstance. And there will be some good, some inspired, and a few great poems, now and again, coming from the street, the salon, the trench. Are there awful poems, or, in a way that's worse, decent, dull poems coming out of the workshops? Sure. But many of these writers will become supporters of the arts, will finance presses, go to museums, etc., and that's important. Will I admit that there's a workshop poem? Of course. It's three-quarters of a page in length, starts out with an image or idea, digresses across and down in an open form, is sentimental, ends with an epiphany hidden in an off-handed... blah blah blah. Or no, maybe it's a narrative poem about the present evening, turns into a personal history, ends sadly bemoaning the... Or how about this? The lyric jumps up, makes a few statements about life, fractures into asides, brings in an atrocity, cuts to lyric outbursts, and is as funny as hell. But one day, these models are cracked by a genius, and we all helped get him or her there. My only regret about writing programs is that they get housed, for financial reasons, in English Departments, rather than in Art Departments or off by themselves (San Francisco State's program, among others, is a department unto itself). This position has made us overly conservative; we feel we have to explain ourselves to these guys. Philosophy and linguistics programs have proved to be more interesting influences lately.

But why emphasize what is wrong with the writing program when so much is right with it? Writers can work, in community if they wish, or in isolation if they prefer, apprenticing in much the same way Michelangelo did, within a patron system. Was it biased, did it produce hacks? Definitely. I say, stop the whining! Change the poem. The proliferation of programs has been good. Where before a privileged few got time and money to write, now anyone can go to a program. It hardly matters where or how large the classes are. It's an opportunity, like reading on the subway. Only you get to turn around and say, hey, what do you think of Stevens? 
MC: I'm impressed by your commitment to the environment. Certainly that's true in the poems about the nuclear industry, but throughout your career you seem interested in plumbing how we're "tethered to earth" ("Sea Level"). What's striking about your environmental regard is its inclusion of technology. Indeed, your work is about as far away from traditional "nature poetry" as I can imagine. Yet the attempt to find an adequate expression and representation of our compact with the earth seems absolutely necessary, particularly in this dangerously war-frothed moment.

JM: My engagement with environmental issues, as you phrase it, began unconsciously. As a child, in New York, I rode my bicycle everywhere. I had an appetite for discovering new places. My parents loved the ocean, and we would travel south every year to visit the Florida coast. In summer, my parents rented a cottage in upstate New York in an enclave with other family members. I also read a lot. I felt alone as a child, even though I had an older brother. When I went to college, the natural world drew me out of myself. Even though I was "popular" in college, I felt awkward, lost in psychosexual issues. Fortunately, I was an explorer. Places never disappoint me. Years later, after a great heartache, I ended up house-sitting for a friend in Santa Fe, caring for her animals and, as it turned out, rehabilitating myself. It was there that I started to "get" what was going on at Los Alamos. My poetry jerked itself inside out to try to fit new information into my old style.

At a certain point, foregrounding the soul's journey seemed wrong. Suddenly, the outside world leapt in. My God, what a relief! But immediately, what a terror and a challenge. The ballads Lorca wrote all his short life, homages to folk culture, earth, food, color, seasons, these really inspired me; one comes to know and love him without "knowing" what time he liked to get up in the morning, what hurt him as a child, etc. Here is Lorca, passionately in the world, reminding us, with his enthusiasm, about kerchiefs, glacier water, green hair. Green hair? His supra-real representations of reality stun and free us. His presentations revive our primordial connections.

Earth seems perpetually wounded. Though I think the bard/ troubadour thing is dead-too precious-I fall on the side of Whitman and Crane in at least trying to take on my American-ness. I really respect Levertov, who saw herself as a Poet in the World. 
To me, that means the current one, behind which are shadows, myths, dreams, sentimentalities, and errors to address. As far as the Sonoran desert, my home, is concerned, one need look no further than out the window to see the pain saguaro cacti are in. They have a short root system, and any effort to move them-by law, they cannot be uprooted for new construction without being replanted-basically destroys them. All over Tucson, condos are "sprouting"-our city's euphemism - and one sees a front line of saguaro cacti circling them, representing what had to be moved to build homes. These are the replants, eerily like the line of redwoods left along Highway 101 in northern California, behind which the forest has been logged. Only in this case, the curtain of subterfuge lasts maybe a year. Saguaros are too fragile to move (although Native American poet Joy Harjo says they move freely at night, returning to their places by morning!). I'm going on about this, and it's not because I'm an environmentalist, or scientist, or activist. It's hitting everybody that the ground is ticking, for example, under the earth, where we have hidden our nuclear garbage. The beautiful Southwest is ticking. There's no question that our consciousnesses are raised about this. I hope I am a "nature poet," with Lorca as my model.

MC: Since we've been talking a lot about morality, what can American poets do to more forcefully engage the world.

JM: The poet Bei Dao recently spoke to our group here at Arizona from what I will call "the other side." What I mean is, he had come back from a trauma. He spoke to us softly, and calmly. In manner, he seemed no different from how I imagine, say, Emily Dickinson, back from heartache, or Whitman, after the Civil War, or Robert Lowell, after mental instability. The "formal feeling" Dickinson wrote of can be achieved only by force of instinct. Poets on any subject, with any rhetorical strategy, can, as you put it, "more forcefully engage the world," if they accustom themselves, it seems to me, to living with paradox. Isn't that the nature of reality, and of art? I do not know if such experiences, which are essentially spiritual, will prepare Americans more profoundly for the world, but we have got to find a way to offer more of our unselfish attention. 